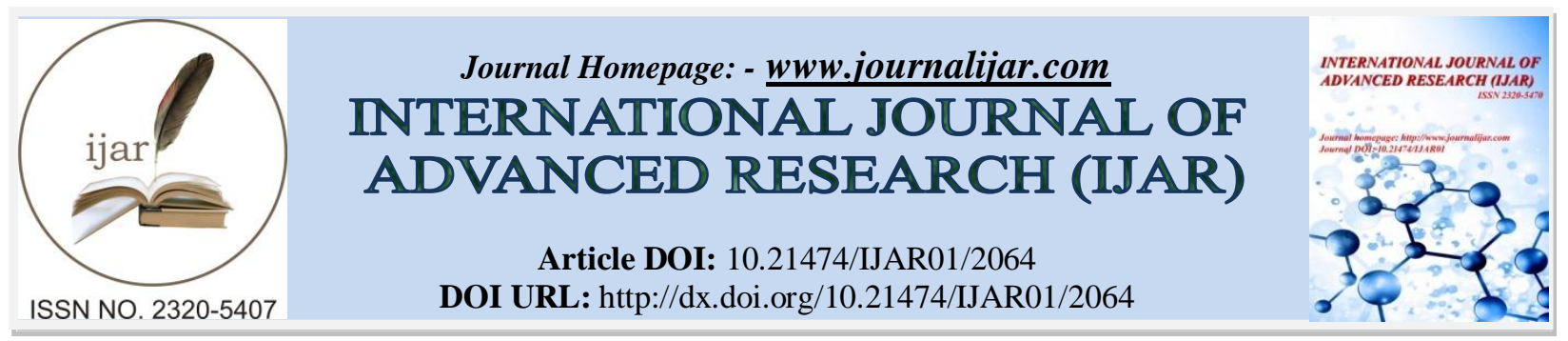

RESEARCH ARTICLE

\title{
EMBRYO VITRIFICATION ON DAY2 AT 4-CELL STAGE USING CRYOLOOP DEVICE: OUR EXPERIENCE.
}

VDS Jamwal, Mohanlal K, Sandeep K, Nikita Naredi and Mohan Angadi.

\section{Manuscript Info}

Manuscript History

Received: 23 September 2016

Final Accepted: 25 October 2016

Published: November 2016

\begin{abstract}
Vitrification of human embryos using cryoprotectants was established as the method for human embryo cryopreservation. Vitrification using cryotop container kit was advocated by Kuwayama et al as a simple and rapid method of cryopreservation. Vitrification has proved to be a better choice in comparison to slow freezing with higher survival rates of cleavage stage embryos. Embryo vitrificationcan be done at the day2, day3 or day5 at 4-cell, 8-cell and blastocyst stages respectively. Embryo vitrification on day 2 at 4- cell stage using cryoloop device is a practical and proven method of cryostorage of human embryos in an ART programme.
\end{abstract}

Copy Right, IJAR, 2016,. All rights reserved.

\section{Introduction:-}

Cryopreservation techniques especially slow freezing were initially practised in cattle and subsequently were applied in other domestic animals. However, the first attempt at embryo vitrification was reported in 1985 [1]. Vitrification avoids the ice formation and establishes a glassy state in which the translational motions of the molecules are arrested without structural reorganisation of the liquid in which embryos are suspended. High cooling rates and high concentration of the cryoprotectants are used to achieve glass like solidification of embryos. The vitrification solutions donot freeze at high cooling rates to very low temperature. The success of vitrification depends upon the very small amount of vitrification medium that must be cooled with very low temperatures $\left(-192\right.$ to $\left.-196^{\circ} \mathrm{C}\right)$ in various types of cryostorage devices. Thus, vitrification is the solidification of a solution at low temperature by extreme increase in viscosity [2]. The rapid temperature change can cause disruption of cellular skeleton and has a damaging effect on the plasma membranes of the embryos. The main limitation of vitrification is the high concentration of cryoprotectants used and the fears of their embryotoxicity. It has been proved that the use of $15 \%$ ethylene glycol used in an equimolar mixture of dimethyl sulfoxide in a frozen embryo transfer had no adverse effects on embryo development as compared to afresh embryo transfer [3]. Vitrification has proved to be a simple, inexpensive, robust and consistent method of cryopreservation in comparison to slow freezing [4]. Vitrification of pronuclear stage embryos has shown cleavage rates on day2 greater than $80 \%$ and blastocyst formation rates of $31 \%$ $[5,6,7]$. Vitrification has proved to be a better choice in comparison to slow freezing with higher survival rates of cleavage stage embryos[8]. A meta-analysis and systemic review was done by Loutradi et al by comparing traditional and cleavage stage embryos found a survival rate of $97 \%$ for vitrification and $84 \%$ for slow freezing [9]. Higher clinical pregnancy rates and implantation rates were reported with vitrification, thus proving its superiority over the slow freezing methods $[10,11]$. 


\section{Material and Methods:-}

A number of studies have been carried on the vitrification of Day 3 human embryos and on the blastocysts. However, there is a dearth of research studies on the vitrification of Day 2 embryos. This is a retrospective study is an attempt to share our experience with the vitrification of Day 2 embryos which was carried in the tertiary care hospital setting. Data from all patient records whose embryos underwent vitrification-warming cycles from January2010 to December 2014 were analyzed. A total of 1,684 warming cycles were subject to analysis. Embryo cryopreservation had been performed on day 2. Data was generated in the form of total vitrification-warming cycles carried out, patients age, no of embryos vitrified, no of thawed embryos transferred, biochemical pregnancies, clinical pregnancies, implantation rate and the ongoing pregnancy rate. All the patients undergoing vitrificationwarming cycle for severe OHSS and for any uterine factor were included in the study. Patients with HIV, hepatitis B and HCV infections were excluded from the study.Vitrification of embryos was carried outusing a two-step protocol with DMSO, ethylene glycol and sucrose as thecryoprotectant agents. Cryoloops (vitrolife) were covered witha film of cryoprotectant and loaded with 2-3 embryos. Cleavage stage embryoswith less than $20 \%$ fragmentation were cryopreserved on Day 2 atthe 4-cell stage. Upon warming embryos were transferred the same after culture in same IVF medium. Patients were prepared for frozen embryo transfer using hormone replacement therapy. All embryos were photographed immediately upon thawing. Embryos were monitored for overall survival of blastomeresand continued development in culture. Other outcome measures included clinical pregnancy and implantation rate. Eighteen days after the embryo transfer beta $\mathrm{hCG}$ values were estimated, with values $>50 \mathrm{IU} / \mathrm{ml}$ taken as the positive. This was confirmed by the presence of the gestational sac on transvaginal sonography 21 days after the embryo transfer.

\section{Results:-}

Human embyros vitrified at the 4- cell stage had excellent post-warming survival rates. Only $6 \%$ of embryos showed any overt indication of cell damage or loss. In a total of 1684 transfers, the clinical pregnancy rate was $48 \%$ $(808 / 1684)$.

Clinical pregnancy was confirmed when an intrauterine gestational sac was revealed by transvaginal ultrasound scan done 5 weeks after embryo transfer [12]. Ongoing pregnancy was defined as a clinical pregnancy with a fetal heartbeat (FHB) at 12 weeks [13] and implantation rate referred to implantation per transferred embryo. Survival, delivery, and live birth rates were determined according to the embryo's developmental stage and morphologic quality at vitrification.

Table 1:-Vitrification on Day 2 at the 4-Cell Stage.

\begin{tabular}{|l|l|}
\hline Age of patient & $23-39$ years \\
\hline Thaws & 1684 \\
\hline Transfers & 1684 \\
\hline Embryos thawed & 3257 \\
\hline Number of embryos transferred & $1-3$ \\
\hline Positive beta hCG & $65 \%$ \\
\hline Clinical pregnancy & $48 \%$ \\
\hline Implantation rate/embryo & $25 \%$ \\
\hline
\end{tabular}

\section{Discussion:-}

Vitrification technique using cryoloop device is an established method of human embryo cryopreservation and has significantly reduced the time taken for cryopreservation [1]. The cryoloop method of vitrification significantly reduces the volume of the cryoprotectant solution. This minimizes the cryoinjury but allows higher rates of cooling. However, this method requires gentle handling of the embryos. Vitrification using cryotop container kit was advocated by Kuwayama et al as a simple and rapid method of cryopreservation with better survival rate of thawed embryos [14]. Previous studies showed vitrification using cryoloop device as an effective means of cryopreservation [15]. The use of the nylon mesh also reduces the volume of the cryoprotectant solution and reduces the ice crystal formation by increased cooling rates. This method was shown to be rapid, inexpensive and effective method of embryo cryopreservation. However, there is a chance of few embryos being lost when immersed in the thawing solution [16]. Though the biochemical pregnancy rate shown by beta $\mathrm{hCG}$ values more than $50 \mathrm{IU} / \mathrm{ml}$ was $65 \%$, the acceptable clinical pregnancy rate of $48 \%$ in our study reinforces the fact that vitrification is a simple, rapid and effective method of embryo cryopreservation in an ART programme. Due to the warming of the embryos in the 
thawing solution and dilution of the cryoprotectants surrounding the embryos, there occurs a sudden uptake of water by the blastomeres leading to rapid expansion of the embryos. There have been published reports of embryo cell damage and poor survival of thawed embryos $[17,18,19]$. Experiments have shown that there is a theoretical risk of bacterial and virological contamination of cryopreserved embryos in the liquid nitrogen during cryostorage, though no such risks have been demonstrated in humans [20,21]. Studies on cryopreserved embryos demonstrated that the cryoloop device can be used for embryo cryostorage by supercooling the air inside the cryovial. Use of both the conventional and the pulled sealed straws is a standard, sterile cryopreservation technique for cryostorage of embryos in liquid nitrogen [22]. Cryotips were advocated as the safe device options for cryostorage [23]

\section{Conclusion:-}

In this study we report retrospective data of four years of experience with day 2 vitrification. To the best of our knowledge this study represents one of the largest studies till date in India with Day 2 vitrification and clinical pregnancy. It is concluded that embryo vitrification on day 2 at 4- cell stage using cryoloop device is a practical and proven method of cryostorage of human embryos in an ART programme.

\section{References:-}

1. Rall WF, Fahy GM. Ice- free cryopreservation of mouse embryos at $-196^{\circ} \mathrm{C}$ by vitrification. Nature.1985; 313:573-5.

2. Fahy GM, et al. Vitrification as an approach to cryopreservation .Cryobiology.1984; 21:407-26.

3. Liebermann J, Tucker MJ. Comparison of vitrification versus conventional cryopreservation of day5 and day6 blastocysts during clinical application. Fertil Steril.2006; 86:20-6.

4. Liebermann J, Tucker MJ. Vitrifying and warming of human oocytes, embryos and blastocysts: vitrification procedures as an alternative to conventional cryopreservation methods. Mol Biol.2004; 254:345-64.

5. Park SP, et al. Ultra rapid freezing of human multipronuclear zygotes using electron microscope grids. Hum Reprod.2000; 15:1787-90.

6. Jelinkova L, et al. Twin pregnancy after vitrification of 2-pronuclei human embryos. Fertil Steril.2002;77:4124.

7. Al Hasani S, Ozmen B, Koutlaki N, Schoepper B, Diedrich K, Schultze-Mosgau A. Three years of routine vitrificationof human zygotes: is it still fair to advocate slow rate freezing? Reprod Biomed Online.2007; 14:288-93.

8. Jericho H, Wilton L, Gook DA, Edgar DH. A modified cryopreservation method increases the survival of human biopsied cleavage stage embryos. Hum Reprod.2003; 18(3):568-71.

9. Loutradi KE, Kolibianakis EM, Venetis CA Papanikolaou EG, Pados G, Bontis I, Tarlatzis BC. Cryopreservation of human embryos by vitrification or slow freezing: a systematic review and meta-analysis. Fertil Steril.2008; 90:186-93.

10. Desai N, Blackmon H, Szeptycki J, Goldfarb J.Cryoloopvitrification of human day3 cleavage stage embryos: post vitrification development, pregnancy outcomes and live births. Reprod Biomed Online 2007; 14:208-13.

11. Balaban B, Urman B, Ata B, Isiklar A, Larman MG, Hamilton R, Gardner DK. A randomized controlled study of human day3 embryo cryopreservation by slow freezing or vitrification :vitrification is associated with higher survival, metabolism and blastocyst formation. Hum Reprod.2008; 23:1976-82.

12. Zegers-Hochschild F, Adamson GD, de Mouzon J, et al. The International Committee for Monitoring Assisted Reproductive Technology (ICMART) and the World Health Organization (WHO) Revised Glossary on ART Terminology, 2009. Hum Reprod 2009; 24:2683-7.

13. Bonduelle M, Liebaers I, Deketelaere V, et al. Neonatal data on a cohort of 2889 infants born after ICSI (1991$1999)$ and of 2995 infants born after IVF (1983-1999). Hum Reprod 2002; 17:671-94.

14. Kuwayama M. Highly efficient vitrification for cryopreservation of human oocytes and embryos: the Cryotop method. Theriogenology2007;67:73-80.

15. Mukaida T, Nakamura S, Tomiyama T, Wada S, Kasai M, Takahashi K. Successful birth after transfer of vitrified hum blastocysts with use of a cryoloopcontainerlesstequnique. FertilSteril 2001; 76:618-20.

16. Akira Nakashima et al. Optimization of novel nylon mesh container for human embryo ultrarapidvitrification. FertilSteril 2010; 93:2405-10.

17. Isachenko V, Montag M, Isachenko E, Nawroth F, Dessole S, Ven H. Developmental rate and ultrastracture of vitrified human pronuclear oocytes after step-wise versus direct rehydration. Hum Reprod 2004; 19:660-5.

18. Hyon JC, Weon YS, San HT, Suk WL, Jin HL. An improved protocol for dilution of cryoprotectants from vitrified human blastocysts. Hum Reprod 2002; 17:2419-22. 
19. Kasai M, Ito K, Edashige K. Morphological appearance of the cryopreserved mouse blastocyst as a tool to identify the type of cryoinjury. Hum Reprod 2002; 17:1863-74.

20. Bielanski A, Nadin-Davis S, Sapp T, LutzeWallacen C. Viral contamination of embryos cryopreserved in liquid nitrogen. Cryobiology 2000; 40:110-6.

21. Bielanski A, Bergeron H, Lau PC, Devenish J. Microbial contamination of embryos and semen during long term banking in liquid nitrogen. Cryobiology 2003; 46:146-52.

22. Chen SU, Lien YR, Chen HF, Chao KH, Ho HN, Yang YS. Open pulled straws for vitrification of mature mouse oocytes preserve patterns of meiotic spindles and chromosomes better than conventional straws. Hum Reprod 2000; 15:2598-603.

23. Kuwayama M, Vajta G, Kato O, Leibo SP. Highly efficient vitrificationmethod for cryopreservation of human oocytes. Reprod Biomed Online2005; 11:300-8. 